\title{
NESTROFT AS SCREENING TEST FOR BETA THALASSEMIA TRAIT
}

KEY WORDS: NESTROFT, Beta Thalassemia Trait

\section{Dr. Keshav Bansal}

\section{Dr. Dhaval Bhatt*}

\section{Dr. G.K. Sharma}

PG Resident, Department of Pediatrics, Government Medical College, Kota.

Assistant Professor, Department of Pediatrics, Government Medical College, Bhavnagar. *Corresponding Author Assistant Professor, Department of Pediatrics, Government Medical College, Kota.

OBJECTIVE: To evaluate the utility of NESTROFT as a screening test for Beta Thalassemia Trait. MATERIAL AND METHODS: A Prospective study of total 137 clinically normal siblings of thalassemia major patients registered at thalassemia clinic in department of pediatrics, Govt. medical college, Kota were selected randomly for the study. All cases were investigated for CBC, Mentzer's index, NESTROFT and HbA2 estimation by HPLC method. RESULT: Total 137 cases were screened for thalassemia carrier by HbA2 estimation using HPLC technique. Total 67 (48.90\%) cases having $\mathrm{HbA} 2$ level $\geq 3.5 \%$ considered as carrier whereas rest 70 (51.10\%) cases were normal. In this study 95 cases showed $\mathrm{MCV}<80$. Out of them 59 cases were carrier and 36 cases were normal. The Sensitivity, specificity, positive predictive value and negative predictive value of $\mathrm{MCV}<80$ are $90.12 \%, 49.71 \%, 63.78 \%$ and $84.68 \%$ respectively. The Sensitivity, specificity, positive predictive value and negative predictive value of Mentzer index are $85.25 \%, 97.16 \%, 96.45 \%$ and $89.19 \%$ respectively. In present study, NESTROFT were done in all cases, the sensitivity of NESTROF test is $94.21 \%$, specificity is $89.72 \%$, Predictive value of positive test is $89.17 \%$ and Predictive value of negative test is $93.75 \%$. So NESTROFT is better test for screening for Beta Thalassemia trait. CONCLUSION: NESTROF test is reliable, cost effective and better screening test for Thalassemia carrier detection. Positive cases can be confirmed by HPLC.NESTROFT can be used as mass screening programme for hemoglobinopathies.

\section{INTRODUCTION}

Thalassemia is the common monogenic disorder. Incidence of beta thalassemia trait in India is around 3.3\%. Prevalence of thalassemia trait varies form $1.0-14.9 \%$ in various regions of India [1]. If we draw a line between Mumbai and Kolkata on the Indian map, in the region above the line the incidence of Thalassemia minor is higher (3-17\%), where as in the region below the line incidence is less than $3 \%$. Incidence is different in various communities, religions and ethnic group [2]. It is estimated that more than 25 million people in India, are carriers of the -thalassemia gene and 8000 children are born every year with thalassemia major. Only 10 to $15 \%$ of these children receive optimal treatment. The cost of such treatment increases as the child grows [3,4]. The only definitive treatment available today is bone marrow transplantation. The birth of a thalassemic child, thus, places considerable physical, physiological and economic burden, not only on the affected child and its family, but also on the community and the nation at large. With these limitations, along with the treatment, measure for prevention of such births in the future should be undertaken [5]. Community control of hemoglobinopathies relies mainly on outreach educational programmes and genetic counseling with antenatal diagnosis [6]. Accurate and timely detection of various hemoglobin variants including beta thalassemia trait can prevent occurrence of more serious disorder like Thalassemia major in newborn [7].

\section{Various methods for screening of Thalassemia carrier are follows}

Red cell indices: Beta Thalassemia traits in general have reduced mean corpuscular volume (MCV) and mean corpuscular hemoglobin (MCH) with normal mean corpuscular hemoglobin concentration (MCHC). Cut off value for each index varies from laboratory to laboratory. Low MCV or MCH sometimes poses a problem by giving false positive results due to iron deficiency anemia.

Naked Eye Single Tube Red Cell Osmotic Fragility Test (NESTROFT): NESTROFT is a rapid, simple and cost effective screening test. The principle of NESTROFT is based on the limit of hypotonicity on which the red cell can withstand. The use of NESTROFT has been recommended for mass screening due to its low cost and simplicity.

HbA2 determination: The hallmark of diagnosis for classical beta thalassemia carriers is a raised $\mathrm{HbA} 2$ varying between $3.5 \%$ and $4 \%$ depending on the method of estimation used. In present study, we evaluated the efficacy of NESTROFT (Naked Eye Single Tube Red Cell Osmotic Fragility Test) in comparison with various other screening parameters in the siblings of thalassemia major patients.

\section{MATERIAL AND METHOD}

This prospective study was conducted at the department of Pediatrics, Government Medical College, Kota. All children who were siblings of thalassemia major patients registered at thalassemia clinic were included in the study. Total 137 cases were enrolled in the study. Careful history was taken. Cases that had history of blood transfusion in last one month and acute febrile illness were excluded from our study. Family history was taken for consanguineous marriage, hemolytic anemia and other significant illnesses. General physical examination including vitals and anthropometry were done followed by systemic examination. After that, $5 \mathrm{ml}$ blood was collected and sent for following investigations:

1. Complete Blood Count: Hemoglobin, RBC count, Hematocrit, Red cell distribution width, MCV, MCH, MCHC, WBC counts, Platelet counts.

\section{NESTROFT (Naked eye single tube red cell osmotic} fragility test): This is used to assess osmotic fragility of red cells at a single concentration of buffered saline $(0.36 \%$ in single tube) visually without a spectrophotometer. A stock solution of $10 \%$ buffered saline (pH 7.4) was prepared by taking NaCl-90g, Na2HPO4-13.655g, NaH2PO4. 2H2O-2.4 g and dissolving them in one liter of distilled water. $0.36 \%$ saline was prepared by dilution of this solution. A positive NESTROFT indicates that all red cells in the tested sample have not undergone lysis in $0.36 \%$ buffered saline. These unlysed red cells result in the hazy appearance of the contents of the tube and render the line on the paper indistinct. Thus a positive NESTROFT indicates decreased red cell osmotic fragility and increased resistance to osmotic lysis. 
3. High performance liquid chromatography (HPLC): For $\mathrm{HbA} 2$ estimation. Data obtained were tabulated using SPSS. Chi-square test and Student't' test were used for statistical analysis.

\section{RESULT}

Total 137 cases were screened for carrier of Thalassemia Major by HPLC method for HbA2 estimation. Total 67 $(48.90 \%)$ cases showed $\mathrm{HbA} 2$ level $\geq 3.5 \%$, considered as carrier while rest $70(51.10 \%)$ cases were normal. The mean $\mathrm{HbA} 2$ value among carriers was $5.33 \%$ in contrast to $2.71 \%$ among rest of normal cases which is statistically significant $(\mathrm{p}<0.0001)$

The difference of Mean MCV between Carriers (65.33fl) and normal cases (80.07fl) was also statistically significant. MCV is key indicator for diagnosis and screening. The mean $\mathrm{MCH}$ among thalassemia carriers was $20.27 \mathrm{pg}$ which was significantly lower than normal cases $26.32 \mathrm{pg}$ ( $\mathrm{p}$ value $<0.001)$. Low $\mathrm{MCH}$ and MCV suggest possibility of thalassemia. In our study 95 cases showed MCV $<80 \mathrm{fl}$ out of which 59 cases were carrier $(\mathrm{HbA} 2>3.5 \%)$ and 36 cases were normal. In our study the Sensitivity, specificity, positive predictive value and negative predictive value of $\mathrm{MCV}<80$ are $90.12 \%, 49.71 \%, 63.78 \%$ and $84.68 \%$ respectively.

We calculated Mentzer index (MCV/TRBC) of each case. Value less than 13 was considered positive for screening of carrier. The Sensitivity, Specificity, positive predictive value and negative predictive value of Mentzer index are $85.25 \%$, $97.16 \%, 96.45 \%$ and $89.19 \%$ respectively.

NESTROF test was done in each case. Cases having NESTROFT positive were 69 . Out of them 61 cases were carrier and 8 cases were normal. NESTROFT was negative in 6 carriers and in 60 normal cases. The Sensitivity of NESTROF test is $94.21 \%$, specificity is $89.72 \%$. False positive cases were $5.81 \%$. False negative cases were $3.37 \%$. Predictive value of positive test is $89.17 \%$ and Predictive value of negative test is $93.75 \%$.

\section{DISCUSSION}

Present study was done to evaluate the use of NESTROFT for mass screening. In our study total 137 cases were screened for Thalassemia carrier by HbA2 estimation using HPLC. Total 67 (48.90\%) cases having $\mathrm{HbA} 2$ level $\geq 3.5 \%$ considered as carrier whereas rest $70(51.10 \%)$ cases were normal.

The mean MCV in carrier was $65.33 \mathrm{fl}$ which was statistically significantly lower than the mean MCV in normal cases (80.07fl). MCV is key indicator for diagnosis and screening. Thalassemic individuals have a reduced MCV, and one study has suggested that an MCV $<72$ is maximally sensitive and specific for presumptive diagnosis of thalassemia syndromes [8].

The mean $\mathrm{MCH}$ among carriers of hemoglobinopathies was significantly lower than normal cases in the study. A low $\mathrm{MCH}$ and a low MCV predicts the presence of thalassemia [9]. In this study 95 cases showed MCV $<80$. Out of them 59 cases were carrier and 36 cases were normal. In our study the Sensitivity, specificity, positive predictive value and negative predictive value of $\mathrm{MCV}<80$ are $90.12 \%, 49.71 \%, 63.78 \%$ and $84.68 \%$ respectively. All the parameters are statistically significant $(\mathrm{p}<0.05)$.

Maheshwari et al (1286 cases) used MCV ( $<77 \mathrm{fl}) \& \mathrm{MCH}$ $(<27 \mathrm{pg})$ for screening, and reported the sensitivity $98 \%$ and specificity $92 \%$ [10]. In the study of Mangalani et al (1997), the sensitivity, specificity, $\%$, negative predictive value \& and positive predictive value were $93.7 \%, 40.6 \%, 95.8 \%$ and $32.5 \%$ respectively in 2525 cases [ 4 ]. In the study of BC Mehta et al (2002), the sensitivity, specificity, negative predictive value \& and positive predictive value of $\mathrm{MCV}<77$ were $97.4 \%$,
$29.7 \%, 7.5 \%$ and $28.2 \%$ respectively [6]. In the study of Batebi et al (2012) the sensitivity, specificity, PPV and NPV were 81.3 $\%, 81.7 \%, 81.1 \%$ and $94.9 \%$ respectively [ 11$]$.

Mentzer index (MCV/TRBC) was also used for screening of thalassemia carrier. The Sensitivity, Specificity, positive predictive value and negative predictive value of Mentzer index are $85.25 \%, 97.16 \%, 96.45 \%$ and $89.19 \%$ respectively. The Sensitivity of Mentzer index was $84.6 \%$ in George Klee et al study, $88.7 \%$ in Nishi Madan et al study, and $85.3 \%$ in Sreekantha et al study $[12,13,14]$.

In present study, NESTROFT were done in all cases, the sensitivity of NESTROF test is $94.21 \%$, specificity is $89.72 \%$, Predictive value of positive test is $89.17 \%$ and Predictive value of negative test is $93.75 \%$.

Table 1: Comparison of NESTROFT with various studies

\begin{tabular}{|c|c|c|c|c|}
\hline Study & Sensitivity & Specificity & PPV & NPV \\
\hline Maheshwari et al & $91 \%$ & $95 \%$ & $55 \%$ & $99 \%$ \\
\hline Manglani et al & $94.4 \%$ & $64.2 \%$ & $35.3 \%$ & $97.6 \%$ \\
\hline Thomas et al & $98.7 \%$ & $66.6 \%$ & $87 \%$ & $96.5 \%$ \\
\hline Raghvan et al & $95.5 \%$ & $87 \%$ & $70.5 \%$ & $98.3 \%$ \\
\hline Singh et al & $97.7 \%$ & $83.3 \%$ & $95.5 \%$ & $90.9 \%$ \\
\hline Present study & $\mathbf{9 4 . 2 1 \%}$ & $\mathbf{8 9 . 7 2} \%$ & $\mathbf{8 9 . 1 7 \%}$ & $\mathbf{9 3 . 7 5 \%}$ \\
\hline
\end{tabular}

Table 2: Comparison of NESTROF test with other screening test in present study

\begin{tabular}{|c|c|c|c|c|}
\hline Name of Test & Sensitivity & Specificity & PPV & NPV \\
\hline MCV $<80$ & $90.12 \%$ & $49.71 \%$ & $63.78 \%$ & $84.68 \%$ \\
\hline Mentzer Index & $85.25 \%$ & $97.16 \%$ & $96.45 \%$ & $89.19 \%$ \\
\hline NESTROF test & $94.21 \%$ & $89.72 \%$ & $89.17 \%$ & $93.75 \%$ \\
\hline
\end{tabular}

Table 1 shows that the results of our study are comparable to Manglani et al [4], Thomas et al [5], Maheshwari et al [10], Raghvan et al [15] and Singh et al [16].

Table 2 shows the sensitivity and negative predictive value of NESTROF test is higher than all other methods of screening. Due to higher sensitivity and negative predictive value, NESTROFT can be used as mass screening test.

\section{CONCLUSION}

Hemoglobinopathies can be suspected on the basis of hematological parameters like reduced $\mathrm{MCV}$, reduced $\mathrm{MCH}$, and elevated RBC count disproportionate to hemoglobin level. NESTROF test is reliable, cost effective and better screening test for carrier detection. Positive cases can be confirmed by HPLC. We recommend screening for the carriers, and counsel them to screen the future life partner for thalassemia carrier before marriage, to prevent thalassemia major in their next generation. For screening we recommended NESTROF test. It can also be used in mass hemoglobinopathies screening programme.

\section{REFERENCES}

1. Satpute, Sandeep B, Bankar, Mangesh P, Momin, AA, Bhoite GM, Yadav RD:The Incidence of Thalassemia Trait in Pregnant Women from South Western Maharashtra. Int J Health Science Research April,2012;2(1):103-7.

2. Bobhate SK, Gaikwad ST, Bhaledrao T. NESTROFF as a screening test for detection of Beta-thalassemia trait. Indian J Pathol Microbiol. 2002 Jul;45(3):265-7.

3. Choudhry VP, Desai N, Pati HP, Nanu A. Current management of homozygous beta thalassemia. Indian Pediatr. 1991 Oct;28(10):1221-9.

4. Manglani M, Lokeshwar MR, Vani VG, Bhatia N, Mhaskar V. 'NESTROFT'--an effective screening test for beta thalassemia trait. Indian Pediatr. 1997 Aug; 34(8):702-7.

5. Thomas S, Srivastava A, Jeyaseelan L, Dennison D, Chandy M. NESTROFT as a screening test for the detection of thalassaemia \& common haemoglobinopathies- an evaluation against a high performance liquid chromatographic method. Indian J Med Res. 1996 Aug; 104:194-7.

6. Mehta BC.NESTROFT: a screening test for beta thalassemia trait. Indian J Med Sci. 2002 Nov; 56(11):537-45.

7. Randolph TR. Thalassemia. In: McKenzie SB, Williams JL, editors. Clinical Laboratory Hematology. 2nd Ed. NewYork: Pearson;2009. p. 231-56.

8. Colah R, Surve R, Wadia M, Solanki P, Mayekar P, Thomas M, Gorakshakar A, Dastur A, Mohanty D. Carrier screening for beta-thalassemia during pregnancy in India: a 7-year evaluation. Genet Test. 2008 Jun; 12(2):181-5. doi: $10.1089 /$ gte.2007.0066.

9. Chopra BS, Nair V, Gupta PK, Mishra DK, Sharma A, Mathew OP. Spectrum of Hemoglobinopathies in a Tertiary Care Hospital of Armed Forces. Medical 
Journal of Armed Forces India 2008;64(4):31 1-14

10. Maheshwari M, Arora S, Kabra M, Menon PS. Carrier screening and prenatal diagnosis of betathalassemia. Indian Pediatr. 1999 Nov;36(11):1119-25.

11. Batebi APA, Esmailian R. Discrimation of betra thalassemia minor and iron deficiency anemia by screening test for red blood cell indices. Turk J Med Sci. 2012;42(2):275-80.

12. Klee GG, Fairbanks VF, Pierre RV, O'Sullivan MB. Routine erythrocyte measurements in diagnosis of iron deficiency anemia and thalassemia minor. Am J Clin Pathol. 1976 Nov;66(5):870-7.

13. Madan N, Sharma S, Sood SK, Colah R, Bhatia LH. Frequency of -thalassemia trait and otherhemoglobinopathies in northern and western India.Indian J Hum Genet. 2010 Jan;16(1):16-25. doi: 10.4103/0971-6866.64941.

14. Sreekantha, Sujatha R, Niveditha S ,Avinash S, Remya,Vinodchandran, Rangaswamy- The study of recent biochemical and pathological aspects of thalassemia. Int J Research in Health Sciences. Oct-Dec 2013;1(3) 140-52.

15. Raghavan K, Lokeshwar MR, Birewar N, Nigam V, Manglani MV, Raju NB. Evaluation of naked eye single tube red cell osmotic fragility test in detecting betathalassemia trait.Indian Pediatr. 1991 May;28(5):469-72.

16. Singh SP, Gupta SC. Effectiveness of red cell osmotic fragility test with varying degrees of saline concentration in detecting beta-thalassaemia trait. Singapore Med J.2008 Oct;49(10):823-6. 